\title{
Adverse Events and Readmissions after Day-Case Urological Surgery
}

\author{
Alvaro Paez, Enrique Redondo, Ana Linares, Emilio Rios, Jorge Vallejo, Margarita \\ Sanchez-Castilla
}

Department of Urology (AP, ER, AL, ER, JV) and Department of Anesthesia (MSC), Hospital De Fuenlabrada, Madrid, Spain

\begin{abstract}
Objective: The literature lacks of studies on postoperative outcomes after urological ambulatory surgery. Our study aims to identify parameters associated with postoperative complications within 30 days after ambulatory urological surgery.

Materials and Methods: Adjusted and unadjusted comparisons between clinical features and postoperative outcome (complicated and uncomplicated).

Results: Postoperative course was complicated in 5\% of the patients. Discharge schedule was not completed in $1.1 \%$ while unplanned visits resulted in admission in $0.5 \%$. Multivariate analyses could only confirm the independent effect of type of anesthesia and diagnosis-related group (DRG) relative weight.

Conclusions: Ambulatory urological surgery can be safe in terms of postoperative complications. In the present study surgery under general anesthesia, or a higher DRG relative weight procedure, increased the risk of complications compared to surgery under regional or local anesthesia or lower DRG relative weight operations. Patients scheduled for general anesthesia or undergoing complex urological procedures should be warned about an increased risk of postoperative incidents and/or readmission.
\end{abstract}

Key words: ambulatory surgical procedures; anesthesia; treatment outcome

Int Braz J Urol. 2007; 33: 330-8

\section{INTRODUCTION}

Ambulatory surgery represents more than 60$70 \%$ of all surgical procedures performed in the United States (1). Considering the extraordinary progress experienced in minimally invasive techniques, this trend will increase during the next years and will probably spread to most surgical specialties. Among modern urologists, there is a growing recognition that many well-established urological procedures may be performed in an ambulatory setting (2). Nevertheless, urological procedures - particularly low-complexity interventions like varicocelectomy and hydrocelectomy - have been identified as an independent risk factor for postoperative complications (3).

Most publications addressing the outcomes of ambulatory surgery reflect observations during patients' stay or within the first 2-3 days after hospital discharge $(4,5)$. This retrospective study aims to identify parameters associated to postoperative complications within 30 days after ambulatory urological surgery. 


\section{MATERIALS AND METHODS}

For this study, the files of all patients undergoing elective ambulatory urological surgery throughout a 16-month period in a single public centre were reviewed. After the pre-operative urological work-up, and once the type of procedure was agreed with the patient, the discharge terms were clarified, paying special attention to those operations requesting an indwelling catheter at discharge (internal urethrotomy for urethral stenosis and resection of female paraurethral cyst).

All patients scheduled for major procedures underwent a pre-anesthesia visit preoperatively. Peripheral blood samples were obtained for cell count and determination of serum concentrations of glucose, total protein, creatinine, sodium, and potassium. Coagulation status was not routinely tested. An electrocardiogram was performed in patients over 45 yearsold. Type of anesthesia was planned in this visit and informed consent was obtained for the procedure.

Only poor-risk cases (ASA 3 or higher) were excluded and operated as inpatients. No age limits were applied. All pediatric patients ( $<11$ years) were operated under general anesthesia (GA); a minimum weight of $15 \mathrm{~kg}$ was used as inclusion criterion in these cases.

General intravenous anesthesia with propofol and remifentanil was the preferred technique also for adult patients undergoing major procedures; drugs were delivered via a TCI (Target Controlled Infusion) pump with target effect in the range of $2-6 \mathrm{mcg} / \mathrm{mL}$ for propofol and 5-10 $\mathrm{ng} / \mathrm{mL}$ for remifentanil. Airway was secured with a laryngeal mask. In pediatric patients, an inhalational technique supplemented with fentanyl was chosen.

Regional anesthesia was performed by the intrathecal route with small gauge (25-27) pencil point needles in the sitting position and an average of 1.5 $\mathrm{mg}$ per dermatome of hyperbaric bupivacaine. Fentanyl $\leq 20$ mcg was added for transurethral procedures.

Typically, patients were sequentially admitted early in the morning, operated and discharged when pain was controlled, and micturition and ambulation confirmed. Perioperative pain was evalu- ated using a visual analog scale (VAS 0 to 10) at arrival in the recovery unit and every 30 minutes. Low-intensity pain (VAS < 3) deserved no analgesia. The standardized treatment for moderate pain (VAS 4-6) was the endovenous administration of a non-steroidal anti-inflammatory drug (NSAID): metamizole $2 \mathrm{~g}$ or ketorololac $30 \mathrm{mg}$ or propacetamol $2 \mathrm{~g}$. Severe perioperative pain (VAS $>7$ ) included the association of endovenous major opioids (fentanyl $0.5-1 \mu \mathrm{g} / \mathrm{kg}$ or morphine $0.03-0.05 \mathrm{mg} / \mathrm{kg}$ or alfentanil 3-5 $\mu \mathrm{g} / \mathrm{kg}$ ). Standard analgesic treatment at discharge was oral metamizole $(500 \mathrm{mg} \mathrm{qd})$, paracetamol (500 mg qd) or ibuprofen (400-600 mg qd). Management of low to moderate perioperative pediatric pain deserved endorectal metamizole (40 $\mathrm{mg} / \mathrm{kg} \mathrm{qd})$, oral $(15 \mathrm{mg} / \mathrm{kg} \mathrm{qd})$ or endorectal paracetamol ( $25 \mathrm{mg} / \mathrm{kg} \mathrm{qd})$, or oral ibuprofen (5-10 $\mathrm{mg} / \mathrm{kg} \mathrm{qd})$. For severe pain, oral tramadol (0.5-1 mg/ $\mathrm{kg} \mathrm{qd)} \mathrm{was} \mathrm{associated.}$

For a safer discharge, pigtail catheters (double $\mathrm{J}$ ) were routinely inserted after ureteroscopy and removed one week later under local anesthesia in the outpatient clinic. Female stress urinary incontinence was treated using retropubic tension-free vaginal tapes. As a general policy, and irrespectively of the procedures, drainages were removed before discharge. When needed patients were instructed about wound and/or sound care. Staff urologists and anesthesiologists were permanently available (roundthe-clock).

For the present study, clinical data (age and gender, type of surgery and anesthesia) were downloaded from the electronic patient record (EPR, Selene, Siemens $\left.{ }^{\circledR}\right)$. For mathematical analysis, all 21 different types of surgery (Table-1) were grouped into four major surgical categories (testicle/scrotum, penis, bladder and ureteroscopy). Diagnosis-Related Group (DRG) relative-weight was used as index of clinical complexity. The DRG system (6) classifies hospital cases into one of approximately 500 groups expected to have similar hospital resource use. DRG relative weights translate the case-mix of patients treated across hospitals.

Postoperative course was the primary outcome measure; for analysis it was considered either uncomplicated (discharge before $10 \mathrm{pm}$ and absence 
Table 1 - Type of surgery and groups for mathematical analysis. Twenty-one different types of surgery were classified into 4 major categories.

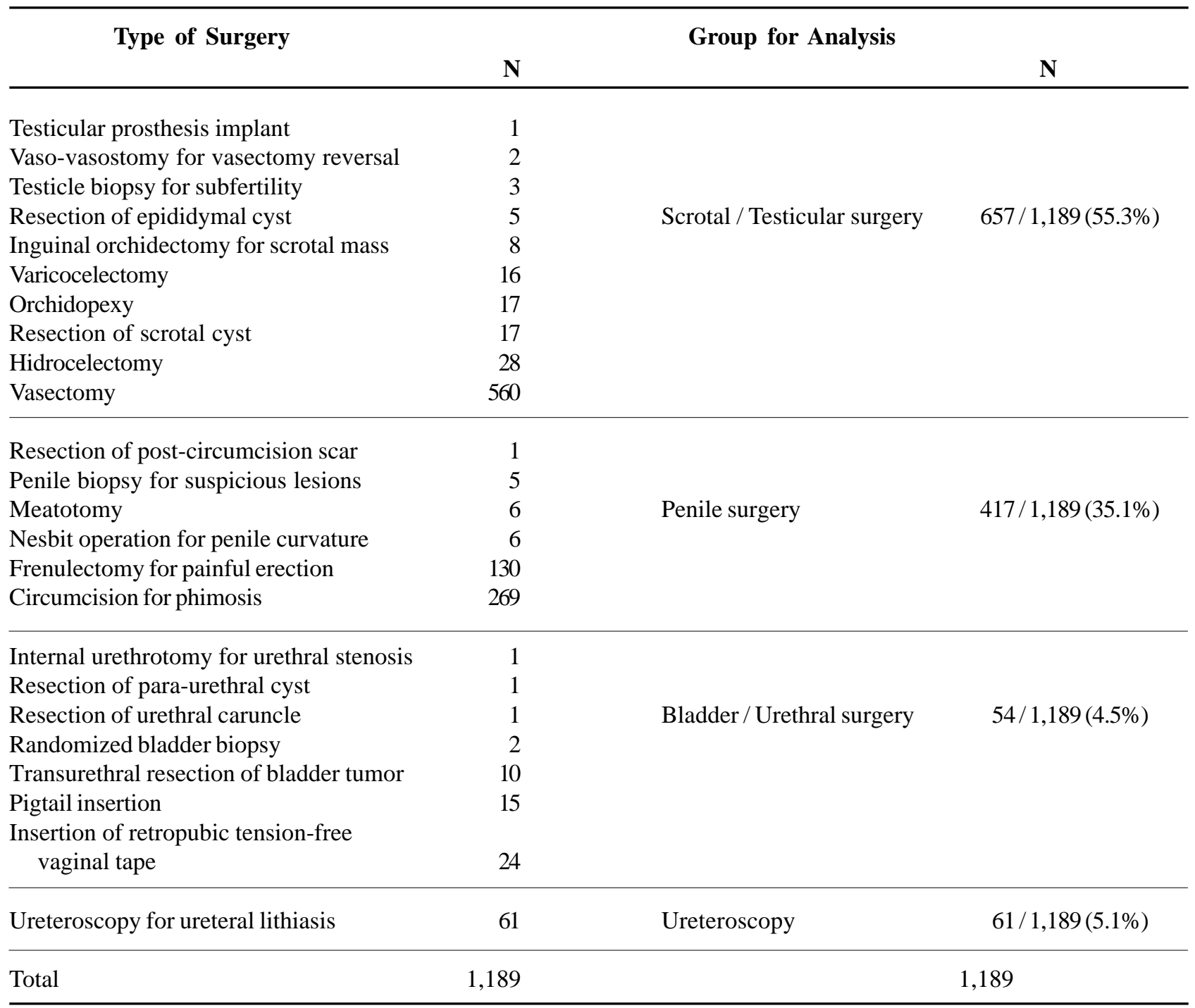

of unplanned visits to outpatients clinic or emergency ward) or complicated (failure to complete the discharge schedule and/or unplanned visits).

An algorithm was created in the EPR to identify the reasons for delaying hospital discharge or warranting unexpected visits to the emergency ward or outpatient clinic within 30 days after surgery.

To identify patients more prone to suffer postoperative complications, univariate comparisons be- tween clinical features and postoperative outcome (uncomplicated or complicated) were performed using the Pearson's chi square and Mann-Withney U tests. Relative risks (RR) for complicated postoperative course were calculated adjusted to every prognostic factor.

To further approach the effect of every variable in the presence of the rest of covariates, logistic regression models were used, taking the postoperative outcome (uncomplicated or complicated) as the 
dependent variable. Additionally, all inpatient admissions were recorded.

Statistical analyses were performed using the SPSS v11.5 statistical software.

A level of significance of $95 \%(\mathrm{p}<0.05)$ was used for all comparisons.

\section{RESULTS}

Throughout the study period, 1,420 consecutive patients were operated on an outpatient basis. Since structured electronic databases were implemented some months after the implementation of daycase urological surgery, only 1,189 cases $(95.1 \%$ men, $4.9 \%$ women, mean age 35.3 years, SD 13.1) were available for analysis. Procedures on testicle/scrotum represented $55.3 \%(657 / 1,189)$ of the total number of interventions, while penile surgery accounted for $35.1 \%(417 / 1,189)$ of all ambulatory operations; ureteroscopy and bladder surgery accounted for $5.1 \%$
$(61 / 1,189)$ and $4.5 \%(54 / 1,189)$ of all ambulatory procedures, respectively (Table-1). We used age as a categorical rather than a continuous variable since the association between age and outcome was not linear but bimodal, thus resulting in two risk groups: low risk (13-59 years) and high risk (older than 59 years + younger than 13 years).

Table- 2 shows patient characteristics, type of surgery, anesthesia and average DRG relative-weight for every category.

Postoperative course was complicated in 59 patients $(59 / 1,189,5 \%)$. Admission of outpatients was decided in $0.5 \%(6 / 1,189)$ and discharge postponed in $1.1 \%(13 / 1,189)$. The remaining $3.4 \%$ presented to the outpatient clinic or emergency ward and could be immediately discharged. Median time to the unplanned visit was 9 days. Post-surgical pain and bleeding or hematuria accounted for the vast majority of complications $(40 / 59,67.8 \%)$. Table-3 shows the distribution of complications.

Table 2 - Distribution of age, gender, type of surgery, type of anesthesia and diagnosis-related group (DRG) relative weight for every category.

\begin{tabular}{|c|c|c|c|}
\hline & & $\mathbf{N}(\%)$ & $\begin{array}{c}\text { DRG Relative Weight } \\
\text { (mean, SD) }\end{array}$ \\
\hline Age group & $\begin{array}{l}<13 y \\
13-29 y \\
30-49 y \\
50-59 y \\
60-70 y \\
>70 y\end{array}$ & $\begin{array}{c}41(3.5) \\
297(25) \\
719(60.4) \\
75(6.3) \\
36(3) \\
21(1.8)\end{array}$ & $\begin{array}{l}0.38,0.12 \\
0.56,0.14 \\
0.46,0.15 \\
0.73,0.28 \\
0.81,0.33 \\
0.71,0.18\end{array}$ \\
\hline Gender & $\begin{array}{l}\text { male } \\
\text { female }\end{array}$ & $\begin{array}{c}1,131(95.1) \\
58(4.9)\end{array}$ & $\begin{array}{l}0.50,0.18 \\
0.85,0.17\end{array}$ \\
\hline Type of surgery & $\begin{array}{l}\text { Scrotal / Testicular surgery } \\
\text { Penile surgery } \\
\text { Bladder surgery } \\
\text { Ureteroscopy }\end{array}$ & $\begin{array}{l}657(55.3) \\
417(35.1) \\
54(4.5) \\
61(5.1)\end{array}$ & $\begin{array}{l}0.42,0,10 \\
0.56,0,16 \\
1.00,0.29 \\
0.73,0.0001\end{array}$ \\
\hline Type of anesthesia & $\begin{array}{l}\text { Local } \\
\text { Regional } \\
\text { General }\end{array}$ & $\begin{array}{l}963(81) \\
108(9.1) \\
118(9.9)\end{array}$ & $\begin{array}{l}0.46,0.10 \\
0.88,0.29 \\
0.65,0.20\end{array}$ \\
\hline
\end{tabular}

$S D=$ standard deviation; $y=$ years. 
Table 3 - Distribution of complications.

\begin{tabular}{lr}
\hline Complication & N (\%) \\
\hline None & $1,130(95 \%)$ \\
Post-surgical pain & $23(1.9 \%)$ \\
Local bleeding / Hematuria & $17(1.4 \%)$ \\
Stranguria / Urinary retention & $7(0.6 \%)$ \\
Fever $\left(>38^{\circ} \mathrm{C}\right)$ & $6(0.5 \%)$ \\
Local infection / Wound dehiscence & $5(0.4 \%)$ \\
Bladder perforation & $1(0.2 \%)$ \\
Total & $1,189(100 \%)$ \\
\hline
\end{tabular}

Age acted as a prognostic factor, with patients $<13$ and $>60$ years old being more exposed to complicated postoperative courses (chi square < $0.001)$. RR for this category was 3.4 (95\% CI 1.8$6.6, \mathrm{p}<0.001)$; in other words, the probability of suffering a complicated postoperative course was almost 3.5 times higher for patients $<13$ and $>60$ years old when compared with patients aged 13-59 years (referent category).
A clear although non-significant trend towards more complicated postoperative courses was detected among women operated as day cases (chi square = 0.053, RR 2.34, 95\% CI .95-5.7, $\mathrm{p}=0.06$ ).

A clear grading in terms of procedure-related postoperative complications was evident, being testis/ scrotum surgery (reference category) associated with the lowest rate of adverse events $(22 / 657,3.3 \%)$, whereas increased rates were observed for penile surgery (19/417, 4.6\%, RR 1.37, 95\% CI .73-2.57, p $=0.31)$, bladder surgery $(7 / 54,13 \%$, RR $4.29,95 \%$ CI 1.74-10.58, $\mathrm{p}=0.002)$ and ureteroscopy $(11 / 61$, $18 \%$, RR 6.35, 95\% CI 2.91-13.83, p < 0.001).

GA resulted in the highest proportion of complicated postoperative courses when compared to regional or local anesthesia (chi square $<0.001$ ). The risk of postoperative complications following regional anesthesia was 6.89-fold (RR 6.89, 95\% CI 3.46-13.75, $\mathrm{p}<0.001$ ) that of local anesthesia (reference category). Surgery under GA had a risk of postoperative complications almost 10-fold higher than surgery using local anesthesia (RR 9.8, 95\% CI 5.23-18.35, p < 0.001).

Table 4 - Results of the univariate risk factor analysis.

\begin{tabular}{|c|c|c|c|c|c|c|c|}
\hline \multirow[t]{2}{*}{ Patient Variable } & & \multicolumn{6}{|c|}{ Clinical Outcome } \\
\hline & & Uncomplicated & Complicated & p Value & $\mathbf{R R}$ & $95 \% \mathrm{CI}$ & p Value \\
\hline $\begin{array}{l}\text { Age group } \\
\text { dichotomized }\end{array}$ & $\begin{array}{c}13-59 \\
<13+>59\end{array}$ & $\begin{array}{r}1,045(95.8 \%) \\
85(86.7 \%)\end{array}$ & $\begin{array}{l}46(4.2 \%) \\
13(13.3 \%)\end{array}$ & $<0.001$ & & Referent & \\
\hline Gender & $\begin{array}{l}\text { male } \\
\text { female }\end{array}$ & $\begin{array}{r}1,078(95.3 \%) \\
52(89.7 \%)\end{array}$ & $\begin{array}{l}53(4.7 \%) \\
6(10.3 \%)\end{array}$ & 0.053 & $\begin{array}{l}3.4 \\
2.34\end{array}$ & $\begin{array}{c}1.8-6.6 \\
\text { referent } \\
0.95-5.7\end{array}$ & $<0.001$ \\
\hline Type of surgery & $\begin{array}{l}\text { Scrotal / } \\
\text { Testicular surgery } \\
\text { Penile surgery } \\
\text { Bladder surgery } \\
\text { Ureteroscopy }\end{array}$ & $\begin{array}{c}635(96.7 \%) \\
398(95.4 \%) \\
47(87 \%) \\
50(82 \%)\end{array}$ & $\begin{array}{l}22(3.3 \%) \\
19(4.6 \%) \\
7(13 \%) \\
11(18 \%)\end{array}$ & $<0.001$ & $\begin{array}{l}1.37 \\
4.29 \\
6.35\end{array}$ & $\begin{array}{l}0.73-2.57 \\
1.74-10.58 \\
2.91-13.83\end{array}$ & $\begin{array}{c}0.31 \\
0.002 \\
<0.001\end{array}$ \\
\hline $\begin{array}{l}\text { Type of } \\
\text { anesthesia }\end{array}$ & $\begin{array}{l}\text { Local } \\
\text { Regional } \\
\text { General }\end{array}$ & $\begin{array}{r}941(97.7 \%) \\
93(86.1 \%) \\
96(81.4 \%)\end{array}$ & $\begin{array}{l}22(2.3 \%) \\
15(13.9 \%) \\
22(18.6 \%)\end{array}$ & $<0.001$ & $\begin{array}{l}6.89 \\
9.8\end{array}$ & $\begin{array}{c}\text { Referent } \\
3.46-13.75 \\
5.23-18.35\end{array}$ & $\begin{array}{l}<0.001 \\
<0.001\end{array}$ \\
\hline \multicolumn{2}{|c|}{ DRG relative-weight } & 0.51 & 0.69 & $<0.001$ & 14.5 & $6.2-34.3$ & $<0.001$ \\
\hline
\end{tabular}

$C I=$ confidence interval $; D G=$ disease-related groups; $R R=$ relative risk; Referent $=$ reference category. 
Complicated postoperative courses had an average DRG relative-weight of 0.69 while uncomplicated cases averaged 0.50 (Mann-Withney U test $<0.001$ ). During the univariate analysis, every DRG relative-weight unit multiplied times-14.5 (RR 14.5, 95\% CI 6.2-34.3, $\mathrm{p}<0.001$ ) the risk of a complicated postoperative course. Table-4 summarizes this phase of the study.

Multivariate analyses could only confirm the independent effect of type of anesthesia and DRG relative-weight. The final model revealed that a hierarchy existed in terms of anesthesia-related complications, with GA resulting in the highest rate of complications (RR 7.6, 95\% CI 3.8-15, $\mathrm{p}=0.003$ ) when compared to the reference category (local anesthesia). Also, DRG relative-weight acted as an independent prognostic factor: every DRG relativeweight unit multiplied times-3.3 (RR 3.3, 95\% CI $1.003-11.4, \mathrm{p}=0.049$ ) the risk of a complicated postoperative course. Predictive regression models are presented in Table-5.

In 19 cases inpatient admission was eventually decided $(6 / 1,189,0.5 \%)$ or discharge was postponed $(13 / 1,189,1.1 \%)$.

\section{COMMENTS}

Although there may be the misconception that ambulatory surgery only deals with minor procedures, the reality is that a wide variety of procedures is commonly performed: in the authors' institution more than 20 different open surgical and endoscopic urologic procedures are routinely performed as day-surgery cases with an average case-mix (mean DRG relative-weight) of 0.52 . Overall, ambulatory surgery represents more than $80 \%$ of the surgical activity in this department were the global DRG relative-weight is 1.38 .

So far, the results can be considered satisfactory with $95 \%$ of patients completing the discharge schedule and not needing any unplanned visit. Similarly, $1.1 \%$ of the patients could not be discharged while $0.5 \%$ had to be readmitted as a result of complications. These rates are consistent with other studies (7-9). The rate of mortality associated with anesthesia and surgery in the outpatient setting has been estimated to be 0.25 to 0.50 per 100,000 outpatient procedures $(7,9)$. As expected, no deaths were identified in the present study (mean patients age $35 \mathrm{yrs}$ ). This finding is also comparable with results published elsewhere (8-12), and translate the levels of safety achieved in ambulatory surgery $(4,13)$.

This study identified two factors affecting the complication rate related to ambulatory urologic surgery: the rate of postoperative complications was strongly dependent on DRG relative-weight and type of anesthesia. Patient-specific factors have been previously identified as important predictors of adverse events: advanced age ( $>85$ years) and comorbidity have been associated with increased risk of inpatient hospital admission $(12,14)$. Also, type of surgery (urological surgery, among others) has been confirmed as a risk factor elsewhere $(3,15)$. In our study, age, while acting as a risk factor during the univariate analysis, could not be confirmed as inde-

Table 5 - Significant results of the multivariate logistic regression model for independent predictors of complicated postoperative course.

\begin{tabular}{lllrr}
\hline Patient Variable & & \multicolumn{2}{l}{ Relative Risk of Complicated Postoperative Course } \\
RR & $\mathbf{9 5 \%}$ CI & palue \\
\hline Type of anesthesia & Local & & Referent & 0.003 \\
& Regional & 3.97 & $1.59-9.88$ & $<0.001$ \\
DRG relative-weight & General & 7.63 & $3.86-15.07$ & 0.049 \\
\hline
\end{tabular}

$C I=$ confidence interval DRG $=$ disease-related groups; $R R=$ relative risk; Referent $=$ reference category. 
pendent risk factor during the multivariate analysis. Nevertheless, it is remarkable that a bimodal curve of risk was identified, with younger $(<13 \mathrm{yrs})$ and elder patients ( $>60 \mathrm{yrs}$ ) being markedly exposed to postoperative complications. In spite of accounting for the lowest clinical complexity (mean DRG relative-weight 0.38 , SD 0.12 ) younger patients experienced the vast majority of complicated postoperative courses. We hypothesize that parents' expectations can sometimes exceed the performance of ambulatory surgery in the pediatric setting thus resulting in an elevated number of delayed discharges and unplanned visits to the hospital. Anyway, children are considered to be excellent candidates for day-case surgery. Pediatric outpatient surgery has been proposed from the age of 4 months (16), and the benefits of a short hospitalization probably justify the modest risk of postoperative incidents and/ or hospitalization (17).

Type of surgery (testicle/scrotum, penis, bladder and ureteroscopy, in this study), while a friendly parameter to clinicians, could not be confirmed as a prognostic variable. In other words, the grouping of surgical procedures used in this study could be sensible for surgical planning but was not helpful to foresee risky operations (in terms of postoperative incidents). On the contrary, we observed an increased risk of postoperative complications associated to clinical complexity as defined by the DRG relative-weight system. It is conceivable that technically demanding procedures can result in postoperative complications but post-surgical outcome is multifactorial with many variables involved. This is the reason why we decided to test the ability of DRG relative-weight to discriminate between patients at risk and not at risk. So far it has been proved that the use of the DRG-system positively affects length of stay (LOS), operative blood loss, transfusion rates, operative margins and postoperative complications, resulting in a higher efficiency $(18,19)$. As far as we know, the DRG relative-weight system has not been used as a prognostic factor for postoperative complications.

The effect of anesthesia on postoperative outcome has been widely studied (20). In a vast study of 17,638 patients, there were no anesthesia-related ad- missions or deaths (10). The type of surgery plays a major role in increasing the postoperative LOS; clearly, urologic patients have longer LOS than those undergoing ophthalmologic surgery (21). In the present study, type of anesthesia (GA) acted as a risk factor for postoperative complications (in terms of discharge and readmission rates) after ambulatory surgery. It is of interest the fact that the level of surgical complexity (in terms of DRG relative-weight) was higher for the group operated under regional anesthesia while patients undergoing GA suffered the vast majority of complications. GA-related side effects probably explain such effect. It is intriguing since a recent experience in healthy men undergoing minor genitourinary procedures proved that GA with remifentanil and propofol was as safe and effective anesthesia as spinal block with the advantage of a faster discharge (22).

Our study has several limitations: the accuracy of our analysis might be biased by its retrospective nature. In addition postoperative complications could be underestimated given no information on visits to general practitioners is available. Other limitations include small sample sizes for ureteroscopy and bladder surgery, and an uneven gender distribution (markedly biased towards male surgery). Also, a number of different procedures was grouped thus making impossible a detailed procedure-specific analysis. From the procedural point of view, we accept that the use of pigtail catheters after uncomplicated ureteroscopy can be arguable $(23,24)$. Nevertheless, our standard is ureteral dilation before the ureteroscope insertion. In this particular setting pig-tails can be warranted (23).

Now, let us be practical. What can be done to improve the performance of day-case urology? Unfortunately, the type of surgery and surgical complexity are factors that cannot be altered preoperatively, while the need for GA cannot be easily modified. Nevertheless patient and staff education offer a window of opportunity for improving the success rate of day-surgery. It has been suggested that the success of ambulatory surgery depends on how attractive it can be for the patient (25). We believe that it also has to be appealing for health-professionals; in the authors' experience upfront procedural informa- 
tion to medical-staff (surgeons, anesthesiologists, nurses and ancillary staff) and patients is vital: the terms of discharge must be clear before patients are included in the waiting list. Otherwise, reasons for delayed discharge can always be identified.

\section{CONCLUSIONS}

Ambulatory urological surgery can be safe in terms of postoperative complications and readmissions. Independently of other clinical factors (age, gender, type of surgery and surgical complexity), surgery under general anesthesia represents a risk factor for postoperative complications and readmission. Similarly, complex procedures (in terms of DRG relative weight) increase the risk of complications compared to low complexity operations. Whenever possible, surgery under regional and/or local anesthesia should be encouraged.

\section{CONFLICT OF INTEREST}

None declared.

\section{REFERENCES}

1. Owings MF, Kozak LJ: Ambulatory and inpatient procedures in the United States, 1996. Vital Health Stat. 1998; 139: 1-119.

2. Mohamed M, Hollins G, Eissa M: Experience in performing pyelolithotomy and pyeloplasty in children on day-surgery basis. Urology. 2004; 64: 1220-3.

3. Twersky R, Fishman D, Homel P: What happens after discharge? Return hospital visits after ambulatory surgery. Anesth Analg. 1997; 84: 319-24.

4. Duncan PG, Cohen MM, Tweed WA, Biehl D, Pope WD, Merchant RN, et al.: The Canadian four-centre study of anaesthetic outcomes: III. Are anaesthetic complications predictable in day surgical practice? Can J Anaesth. 1992; 39: 440-8.

5. Liu LL, Leung JM: Predicting adverse postoperative outcomes in patients aged 80 years or older. J Am Geriatr Soc. 2000; 48: 405-12.

6. Diagnosis Related Groups (DRGs) and the Medicare Program: Implications for Medical Technology - A
Technical Memorandum (Washington, D.C.: U.S. Congress, Office of Technology Assessment, OTA-TMH-17, July 1983).

7. Eichhorn JH: Prevention of intraoperative anesthesia accidents and related severe injury through safety monitoring. Anesthesiology. 1989; 70: 572-7.

8. Mezei G, Chung F: Return hospital visits and hospital readmissions after ambulatory surgery. Ann Surg. 1999; 230:721-7.

9. Shnaider I, Chung F: Outcomes in day surgery. Curr Opin Anaesthesiol. 2006; 19: 622-9.

10. Millar JM: US ambulatory surgery projections are inappropriate. Ambul Surg. 1997; 5: 121-4.

11. Fleisher LA, Pasternak LR, Herbert R, Anderson GF: Inpatient hospital admission and death after outpatient surgery in elderly patients: importance of patient and system characteristics and location of care. Arch Surg. 2004; 139: 67-72.

12. Morello DC, Colon GA, Fredricks S, Iverson RE, Singer R: Patient safety in accredited office surgical facilities. Plast Reconstr Surg. 1997; 99: 1496-500.

13. Natof HE: Complications associated with ambulatory surgery. JAMA. 1980; 244: 1116-8.

14. Marcantonio ER, McKean S, Goldfinger M, Kleefield S, Yurkofsky M, Brennan TA: Factors associated with unplanned hospital readmission among patients 65 years of age and older in a Medicare managed care plan. Am J Med. 1999; 107: 13-7.

15. Coley KC, Williams BA, DaPos SV, Chen C, Smith RB: Retrospective evaluation of unanticipated admissions and readmissions after same day surgery and associated costs. J Clin Anesth. 2002; 14: 349-53.

16. Kalfa N, Forgues D, Rochette A, Lopez M, Guibal MP, Sabatier-Laval E, et al.: [A comparative study of the feasibility and limits of ambulatory surgery in infants under and over one year of age][French]. Ann Chir. 2004; 129: 144-8.

17. Minatti WR, Benavides F, Capelino P, Ramos R, Premoli $G$ and Statti M: Postdischarge unplanned admission in ambulatory surgery-a prospective study. Ambul Surg. 2006; 12: 107-112.

18. Schwartz MH, Tartter PI: Decreased length of stay for patients with colorectal cancer: implications of DRG use. J Healthc Qual. 1998; 20: 22-5.

19. Collier PE: Fast tracking carotid endarterectomy: practical considerations. Semin Vasc Surg. 1998; 11: 41-5.

20. Deutsch N, Wu CL: Patient outcomes following ambulatory anesthesia. Anesthesiol Clin North America. 2003;21:403-15. 
21. Chung F, Mezei G: Factors contributing to a prolonged stay after ambulatory surgery. Anesth Analg. 1999; 89: 1352-9.

22. Erhan E, Ugur G, Anadolu O, Saklayan M, Ozyar B: General anaesthesia or spinal anaesthesia for outpatient urological surgery. Eur J Anaesthesiol. 2003; 20: 647-52.

23. Byrne RR, Auge BK, Kourambas J, Munver R, Delvecchio F, Preminger GM: Routine ureteral stenting is not necessary after ureteroscopy and ureteropyeloscopy: a randomized trial. J Endourol. 2002; 16: 9-13.

24. Denstedt JD, Wollin TA, Sofer M, Nott L, Weir M, D'A Honey RJ: A prospective randomized controlled trial comparing nonstented versus stented ureteroscopic lithotripsy. J Urol. 2001; 165: 1419-22.

25. Calle JE, Parra P, Gomis R, Ramón T and San Eustaquio F: Use of the substitution index to identify improvement opportunities in major ambulatory surgery. Ambul Surg. 2006; 12: 159-166.

\section{Correspondence address:}

Dr. Alvaro Paez

Servicio de Urologia

Hospital de Fuenlabrada

C. del Molino 2

28942, Fuenlabrada, Madrid, Spain

Fax: + 349 1600-6186

E-mail: apaez.hflr@salud.madrid.org 